Pacific Journal of Mathematics

SHOCK SETS FOR FIRST ORDER NONLINEAR HYPERBOLIC 


\title{
SHOCK SETS FOR FIRST ORDER NONLINEAR HYPERBOLIC EQUATIONS
}

\author{
DONALD P. BALLOU
}

This paper studies those values $u$ which can be reached from $u_{0}$ across a shock or contact discontinuity which may arise in weak solutions to the Cauchy problem

$$
\begin{aligned}
& \frac{\partial u}{\partial t}+\frac{\partial F(u)}{\partial x}=0 \\
& u(0, x)=u^{0}(x),
\end{aligned}
$$

where it is not assumed that $F^{\prime \prime}>0$. A condition which guarantees uniqueness is used to define a set $S\left(u_{0}\right)$ consisting of such values $u$. The close relationship between $S\left(u_{0}\right)$ and the geometry of $F(u)$ is examined, and properties of this set are derived which give information about the interaction of curves of discontinuity.

1. Introduction. In this paper we shall study the discontinuities which arise in weak solutions to the Cauchy problem

$$
\begin{aligned}
& \frac{\partial u}{\partial t}+\frac{\partial F(u)}{\partial x}=0, \\
& u(0, x)=u^{0}(x),
\end{aligned}
$$

where $u^{0}(x)$ is a preassigned, bounded, measurable function. The purpose is to relate the values of a solution to the left and right of a discontinuity to the geometry of $F(u)$. To do this we require that

(i) $F \in C^{2}\left(R^{1}\right)$,

(ii) the inflection points of $F$ are isolated.

The second condition is employed to avoid pathological behavior such as is found in Ballou [2].

As is well known (cf. Oleinik [4]), in order to obtain uniqueness it is necessary to impose some condition on the weak solutions. One such condition is due to Volpert (cf. [6]) and it gives uniqueness in the class $B V$ of functions whose generalized derivatives are locally measures. As will be shown in $\S 2$, whenever the weak solution is piecewise smooth, this is equivalent to Condition $E$, which guarantees that characteristics cannot diverge from a curve of discontinuity.

In $\S 3$ by using Condition $E$ we define for each value $u_{0}$ of $u$ a set $S\left(u_{0}\right)$, known as the shock set, which contains those values of $u$ that can be reached from $v_{0}$ by means of either a shock or a contact discontinuity. The close connection between the properties of these 
sets, such as compactness, and the geometry of $F$ is then examined. Also, using the shock sets, conditions are given which guarantee that the interaction of two curves of discontinuity produces exactly one curve of discontinuity. (From [2] it is known that a jump in the initial data can give rise to an infinite number of discontinuities.)

We now give the definitions of some basic concepts.

Definition. A weak solution to the Cauchy problem (1), (2) is a bounded, measurable function $u(t, x)$ which satisfies

$$
\iint_{t>0}\left[u(t, x) \frac{\partial \dot{\phi}}{\partial t}+F(u(t, x)) \frac{\partial \dot{\phi}}{\partial x}\right] d x d t+\int_{t=0} \phi(0, x) u^{0}(x) d x=0
$$

for all $\phi=\phi(t, x) \in C_{0}^{2}\left(R_{+}^{2}\right) . \quad\left(R_{+}^{2}=\{(t, x) \mid t \geqq 0\right.$ and $\left.-\infty<x<\infty\}\right)$.

DEFINITION $^{1}$. Let $x(t)$ be a smooth curve of discontinuity of a weak solution $u(t, x)$ and assume that $u^{ \pm}=\lim _{\varepsilon \backslash 0} u(t, x(t) \pm \varepsilon)$ exist. Then $x(t)$ is a shock provided $F^{\prime}\left(u^{-}\right)>x^{\prime}(t)>F^{\prime}\left(u^{+}\right)$.

The curve $x(t)$ is a contact discontinuity provided $F^{\prime}\left(u^{-}\right)=x^{\prime}(t)$ or $F^{\prime}\left(u^{+}\right)=x^{\prime}(t)$.

2. Equivalence of Volpert's condition and Condition E. In this section we state Volpert's uniqueness condition and Condition E and then establish their equivalence when the weak solution is piecewise smooth. We also derive some consequences of Condition E.

In the following we shall assume that the weak solutions are piecewise smooth.

Volpert's uniqueness condition. Set

$$
T[v ; w]=[a(v)-a(w)] \operatorname{sign}(v-w),
$$

where $a(u)$ is the vector $a(u)=(u, F(u))$. Let $\gamma=\gamma(t)$ be any curve of discontinuity of the weak solution $u(t, x)$, and put $u^{ \pm}=\lim _{\varepsilon \backslash 0} u(t$, $\gamma(t) \pm \varepsilon)$. Then almost everywhere

$$
\left\langle T\left[u^{+} ; c\right], \nu\right\rangle \leqq\left\langle T\left[u^{-} ; c\right], \nu\right\rangle
$$

where $c$ is an arbitrary constant, $\nu$ is the normal to $\gamma$, considered positive to the right, and $\langle$,$\rangle denotes the scalar product of two vectors$ in $R^{2}{ }^{2}$

\section{Condition E. Set}

1 The definitions for shock and contact discontinuity are specializations to the case of one equation of the definitions given by Lak [3] for systems.

2 See Volpert [6] for the definitions of $u^{+}, u^{-}$, and $v$ whenever $u(t, x)$ is not piecewise smooth. 


$$
S[w ; z]=\frac{F(w)-F(z)}{w-z}
$$

Let $\gamma(t)$ and $u^{ \pm}$be as above, and let $v$ be any number lying between $u^{+}$and $u^{-}$. Then almost everywhere

$$
S\left[v ; u^{-}\right] \geqq S\left[u^{+} ; u^{-}\right] \text {. }
$$

Volpert [6] showed that his condition guarantees uniqueness of solutions to (1), (2) in the class $B V$ of functions whose generalized derivatives are measures locally. Wu [7] established that Condition $\mathrm{E}$ gives uniqueness in the class of piecewise smooth functions. We now show that these two conditions are equivalent for piecewise smooth weak solutions.

THEOREM 2.1. Let $u(t, x)$ be a piecewise smooth weak solution. Then Volpert's condition holds if, and only if, Condition $E$ holds.

Proof. We first show that Volpert's condition implies Condition E. Let $x(t)$ be a curve of discontinuity. Since $u(t, x)$ is a piecewise smooth weak solution, the Rankine-Hugoniot condition must hold along $x(t)$; i.e.,

$$
\frac{d x}{d t}=\frac{F\left(u^{+}\right)-F\left(u^{-}\right)}{u^{+}-u^{-}}
$$

Hence the normal can be expressed by

$$
\nu=\left(\nu_{t}, \nu_{x}\right)=\left(-\frac{F\left(u^{+}\right)-F\left(u^{-}\right)}{u^{+}-u^{-}}, 1\right)
$$

By hypothesis

$$
\left\langle T\left[u^{+} ; c\right], \nu\right\rangle \leqq\left\langle T\left[u^{-} ; c\right], \nu\right\rangle
$$

holds for all $c$. Let $c$ lie between $u^{+}$and $u^{-}$, and for the sake of argument suppose that $u^{-}<c^{-}<u^{+}$. Then

$$
T\left[u^{+} ; c\right]=\left(u^{+}-c, F\left(u^{+}\right)-F(c)\right)
$$

and

$$
T\left[u^{-} ; c\right]=\left(c-u^{-}, F(c)-F\left(u^{-}\right)\right) .
$$

From (3) it follows that

$$
S\left[u^{+} ; u^{-}\right]\left(u^{+}+u^{-}-2 c\right) \geqq F\left(u^{+}\right)+F\left(u^{-}\right)-2 F(c) .
$$

If Condition $\mathrm{E}$ should fail to hold for some $c, u^{-}<c<u^{+}$, then it would follow that 


$$
\frac{F(c)-F\left(u^{-}\right)}{c-u^{-}}<\frac{F\left(u^{+}\right)-F\left(u^{-}\right)}{u^{+}-u^{-}}
$$

or

$$
-\left[-F(c)+F\left(u^{-}\right)\right]<-\left[\left(-c+u^{-}\right) \frac{F\left(u^{+}\right)-F\left(u^{-}\right)}{u^{+}-u^{-}}\right] .
$$

Add (6) to (4) to get

$$
\frac{F\left(u^{+}\right)-F\left(u^{-}\right)}{u^{+}-u^{-}} \geqq \frac{F\left(u^{+}\right)-F(c)}{u^{+}-c} .
$$

But by (5) the point $(c, F(c))$ lies below the line joining $\left(u^{-}, F\left(u^{-}\right)\right)$ to $\left(u^{+}, F\left(u^{+}\right)\right)$while by $(7),(c, F(c))$ lies on or above the line, giving a contradiction. Hence Volpert's condition implies Condition E.

To establish the converse, note that if $c$ lies between $u^{-}$and $u^{+}$, then by Condition $\mathrm{E}$

$$
S\left[u^{+} ; c\right] \leqq S\left[u^{+} ; u^{-}\right] \leqq S\left[c ; u^{-}\right] .
$$

Suppose for the sake of argument that $u^{-}<c<u^{+}$.

Hence

$$
S\left[u^{+} ; u^{-}\right]\left(u^{+}-c\right) \geqq F\left(u^{+}\right)-F(c)
$$

and

$$
S\left[u^{+} ; u^{-}\right]\left(u^{-}-c\right) \geqq F\left(u^{-}\right)-F(c) .
$$

Using (8) and (9) it is possible to retrace the steps above to conclude that

$$
\left.\left\langle T\left[u^{+}, c\right], \nu\right\rangle \leqq\left\langle T\left[u^{-}, c\right]\right\rangle, \nu\right\rangle .
$$

If $c \leqq \min \left\{u^{-}, u^{+}\right\}$, then

$$
\begin{aligned}
& \left\langle T\left[u^{-}, c\right], \nu\right\rangle-\left\langle T\left[u^{+}, c\right], \nu\right\rangle \\
= & -S\left[u^{+} ; u^{-}\right]\left(u^{-}-u^{+}\right)+F\left(u^{-}\right) F\left(u^{+}\right)=0 .
\end{aligned}
$$

The same result holds if $c \geqq \max \left\{u^{-}, u^{+}\right\}$.

In the study of weak solutions it is desirable to allow as curves of discontinuity only those that arise naturally as a result of the intersection of characteristics, or in other words to rule out those discontinuities from which characteristics diverge. The sigrificance of Condition $\mathrm{E}$ is that it permits only the desired class of discontinuities. This is established by the following theorem. 
THEOREM 2.2. Let $u(t, x)$ be a piecewise smooth weak solution satisfying Condition $E$ to the Cauchy problem (1), (2), and let $\gamma(t)$ be a curve of discontinuity. Then

$$
F^{\prime}\left(u^{-}\right) \geqq \frac{d \gamma(t)}{d t} \geqq F^{\prime}\left(u^{+}\right) \cdot{ }^{3}
$$

A proof of this theorem is found in [1].

Note. Using the Rankine-Hugoniot condition, the above can be written as

$$
F^{\prime \prime}\left(u^{-}\right) \geqq S\left[u^{+} ; u^{-}\right] \geqq F^{\prime \prime}\left(u^{+}\right) \text {. }
$$

3. Shock sets and their properties. In this section we first define a set which contains those values of $u$ that can be reached from $u_{0}$ across an admissible curve of discontinuity. We then study the properties of these shock sets, with emphasis on examining the relationship between the geometry of $F$ and the sets.

Definition. Let $u_{0}$ be given. Then the shock set $S\left(u_{0}\right)$ contains those values $u$ such that

$$
S\left[v ; u_{0}\right] \geqq S\left[u ; u_{0}\right]
$$

for all $v$ lying between $u_{0}$ and $u$.

NotE. If $u \in S\left(u_{0}\right)$, then $u$ can be reached from $u_{0}$ via a shock or contact discontinuity. Also the set $S\left(u_{0}\right)$ is closed, a fact which follows easily from the definition.

Convention. We let $u_{0} \in S\left(u_{0}\right)$. A consequence of this convention is that if $S\left(u_{0}\right)=\left\{u_{0}\right\}$, then there is no permissible solution of the Riemann problem involving a curve of discontinuity.

THeOREM 3.1. Let $L$ be the tangent line to $F(u)$ at $u=u_{0}$. Then $S\left(u_{0}\right)=\left\{u_{0}\right\}$ if, and only if, the graph of $F$ lies above $L$ for $u>u_{0}$ and below $L$ for $u<u_{0}$.

Proof. First suppose that $S\left(u_{0}\right)=\left\{u_{0}\right\}$. We shall show that the graph of $F$ lies above $L$ for $u>u_{0}$. (The case $u<u_{0}$ follows similarly.) Since the inflection points are isolated, there is a $u_{1}>u_{0}$ such that either $F^{\prime \prime}(u) \geqq 0$ on $I=\left(u_{0}, u_{1}\right)$ or $F^{\prime \prime}(u) \leqq 0$ on $I$. If the second alternative held, then, as can be easily seen,

3 Recall that the characteristics have slope $d x / d t=F^{\prime}(u)$. 


$$
\frac{d}{d v} S\left[v ; u_{0}\right] \leqq 0, \quad v \in I
$$

Hence $S\left[v ; u_{0}\right] \geqq S\left[u_{1} ; u_{0}\right] \forall v \in I$, which implies that $u_{1} \in S\left(u_{0}\right)$, a contradiction. Thus $F^{\prime \prime}(u) \geqq 0$ on $I$, and hence for $u \in I$, the graph of $w=F(u)$ cannot lie below $L$. It remains to show that if $\tilde{u}>u_{0}$, then $(\widetilde{u}, F(\widetilde{u}))$ is not on $L$. To establish this suppose otherwise and choose

$$
\widetilde{u}=\inf \left\{u:(u, F(u)) \text { lies on } L, u>u_{0}\right\} \text {. }
$$

To see that $\tilde{u} \neq u_{0}$, note that otherwise there would be a $\bar{u} \in\left(u_{0}, u_{1}\right)$, $(\bar{u}, F(\bar{u}))$ on $L$. But if $u_{0}<v<\bar{u}$, then

$$
S\left[v ; u_{0}\right]-S\left[\bar{u} ; u_{0}\right]=F^{\prime}(\xi)-F^{\prime}\left(u_{0}\right) \geqq 0
$$

where $u_{0}<\xi<\bar{u}$. Since $\bar{u} \in S\left(u_{0}\right)$ is a contradiction, it follows that $\widetilde{u}>u_{0}$. Since $(v, F(v))$ lies above $L, u_{0}<v<\widetilde{u}$,

$$
F(v)>F^{\prime}\left(u_{0}\right)\left(v-u_{0}\right)+F\left(u_{0}\right),
$$

which implies

$$
S\left[v ; u_{0}\right]>S\left[\widetilde{u} ; u_{0}\right] .
$$

Hence $\tilde{u} \in S\left(u_{0}\right)$, a contradiction.

To establish the converse, suppose there exists $w \in S\left(u_{0}\right), w \neq u_{0}$. Without loss of generality we may assume that $w>u_{0}$. Then by hypothesis

$$
S\left[w ; u_{0}\right]>F^{\prime \prime}\left(u_{0}\right) .
$$

Since $S\left[v ; u_{0}\right] \rightarrow F^{\prime}\left(u_{0}\right)$ as $v \rightarrow u_{0}$, for $v$ sufficiently close to $u_{0}$

$$
S\left[w ; u_{0}\right]>S\left[v ; u_{0}\right],
$$

a contradiction of Condition E.

THEOREM 3.2. Let $L_{u}$ denote the line through the points $\left(u_{0}, F\left(u_{0}\right)\right)$ and $(u, F(u))$. Then $S\left(u_{0}\right)$ is compact if, and only if, there exist $u_{1}$, $u_{2}, u_{1}<u_{0}<u_{2}$, such that the graph of $F(u)$ lies below $L_{u_{1}}$ for $u<u_{1}$ and above $L_{u_{2}}$ for $u>u_{2}$.

Proof. Suppose $S\left(u_{0}\right)$ is compact. Let $u_{1}=\inf S\left(u_{0}\right)$ and $u_{2}=\sup$ $S\left(u_{0}\right)$. Then the graph of $F(u)$ lies above

$$
w=S\left[u_{2} ; u_{0}\right]\left(u-u_{0}\right)+F\left(u_{0}\right) \text { for } u>u_{2} .
$$

If this were not so, then there would exist $\widetilde{w}>u_{2}$ such that 


$$
F(\widetilde{w})=S\left[u_{2} ; u_{0}\right]\left(\widetilde{w}-u_{0}\right)+F\left(u_{0}\right)
$$

and

$$
F(w)>S\left[u_{2} ; u_{0}\right]\left(w-u_{0}\right)+F\left(u_{0}\right), \quad u_{2}<w<\widetilde{w}
$$

Since

$$
S\left[v ; u_{0}\right] \geqq S\left[u_{2} ; u_{0}\right]=S\left[\widetilde{w} ; u_{0}\right] \quad \forall v \in\left(u_{0}, u_{2}\right),
$$

it follows from (10) and (11) that

$$
S\left[v ; u_{0}\right] \geqq S\left[\widetilde{w} ; u_{0}\right] \quad \forall v \in\left(u_{0}, \widetilde{\mathcal{v}}\right) .
$$

Therefore $\widetilde{w} \in S\left(u_{0}\right)$, a contradiction of the definition of $u_{2}$. The proof that $F(u)$ lies below $L_{u_{1}}$ is handled similarly.

Conversely if there is a $u_{2}$ such that the graph of $F(u)$ lies above $L_{u_{2}}$ for $u>u_{2}$, then $w>u_{2}$ implies $w \notin S\left(u_{0}\right)$. For otherwise by Condition $\mathrm{E}$

$$
S\left[u_{2} ; u_{0}\right] \geqq S\left[w ; u_{0}\right]
$$

But from

$$
F(w)>S\left[u_{2} ; u_{0}\right]\left(w-u_{0}\right)+F\left(u_{0}\right), w>u_{0},
$$

it follows that

$$
S\left[w ; u_{0}\right]>S\left[u_{2} ; u_{0}\right],
$$

which together with (12) gives a contradiction. Thus $u_{2}$ is an upper bound for $S\left(u_{0}\right)$. Similarly $u_{1}$ is a lower bound. Hence $S\left(u_{0}\right)$ is compact.

THEOREM 3.3. Let $u_{1}<u_{2}$ and let $u_{2} \in S\left(u_{1}\right)$. Then $S\left(u_{2}\right) \cap\left(u_{2}, \infty\right)$ $\subset S\left(u_{1}\right)$.

Note. This theorem asserts that if it is possible to jump from $u_{1}$ to $u_{2}$ and from $u_{2}$ to $u_{3}$, where $u_{1}<u_{2}<u_{3}$, then it is possible to jump from $u_{1}$ to $u_{3}$. It is interesting to note that this fails to hold for systems (cf. Smoller [5]).

Proof. Let $u_{3} \in S\left(u_{2}\right)$, where $u_{3}>u_{2}$. Then by the note following Theorem 2.2

$$
S\left[u_{2} ; u_{1}\right] \geqq F^{\prime}\left(u_{2}\right) \geqq S\left[u_{3} ; u_{2}\right]
$$

From this it is easily seen that

$$
S\left[u_{2} ; u_{1}\right] \geqq S\left[u_{3} ; u_{1}\right] \geqq S\left[u_{3} ; u_{2}\right] .
$$


To see that $u_{3} \in S\left(u_{1}\right)$, assume otherwise.

Then there is $w \in\left(u_{1}, u_{3}\right)$ such that

$$
S\left[w ; u_{1}\right]<S\left[u_{3} ; u_{1}\right] \text {. }
$$

Since $S\left[w ; u_{1}\right] \geqq S\left[u_{2} ; u_{1}\right] \geqq S\left[u_{3} ; u_{1}\right]$ holds for all $w \in\left(u_{1}, u_{2}\right)$, it follows that $w \in\left(u_{2}, u_{3}\right)$. Since $u_{3} \in S\left(u_{2}\right)$, it follows that

$$
S\left[w ; u_{3}\right] \leqq S\left[u_{3} ; u_{2}\right]
$$

A consequence of (14) is that

$$
S\left[w ; u_{3}\right]>S\left[u_{1} ; u_{3}\right] .
$$

By (15) and (16)

$$
S\left[u_{3} ; u_{2}\right]>S\left[u_{1} ; u_{3}\right]
$$

a contradiction of (13).

For the next result two lemmas are needed.

Lemma 1. If $F^{\prime \prime}>0$ on $\left(u_{0}, u_{1}\right)$, then $S\left(u_{0}\right) \cap\left(u_{0}, u_{1}\right)=\varnothing$.

Proof. It is easily seen that $(d / d v) S\left[v ; u_{0}\right]>0, v \in\left(u_{0}, u_{1}\right)$. Therefore given $v$ and $w$ satisfying $u_{0}<v<w<u_{1}$, it follows that $S\left[v ; u_{0}\right]<$ $S\left[w ; u_{0}\right]$, and hence Condition $\mathrm{E}$ cannot hold.

LemmA 2. If $F^{\prime \prime}>0$ on $\left(u_{1}, u_{0}\right)$, then $S\left(u_{0}\right) \cap\left(u_{1}, u_{0}\right)=\varnothing$.

Proof. The proof is similar to that of Lemma 1 .

THEOREM 3.4. The number $u_{0}$ is an interior point of $S\left(u_{0}\right)$ if, and only if, there exist numbers $u_{1}, u_{2}$ satisfying $u_{1}<u_{0}<u_{2}$ such that $F^{\prime \prime}(u) \geqq 0, u_{1}<u<u_{0}$, and $F^{\prime \prime}(u) \leqq 0, u_{0}<u<u_{2}$.

Note. This theorem gives conditions under which it is possible to jump from $u_{0}$ to any value of $u$ sufficiently close to $u_{0}$.

Proof. Suppose that $u_{0}$ is an interior point. Then there exist $u_{1}$, $u_{2}, u_{1}<u_{0}<u_{2}$, such that $\left(u_{1}, u_{2}\right) \subset S\left(u_{0}\right)$. Choose $u_{1}$ and $u_{2}$ such that on $\left(u_{1}, u_{2}\right)$ the only possible point of inflection of $F$ is $u_{0}$. If $F^{\prime \prime}<0$ held on $\left(u_{1}, u_{0}\right)$, then by Lemma $2, u_{0}$ could not be an interior point of $S\left(u_{0}\right)$. Hence $F^{\prime \prime} \geqq 0$ on $\left(u_{1}, u_{0}\right)$. Similarly $F^{\prime \prime} \leqq 0$ on $\left(u_{0}, u_{2}\right)$.

For the converse let $u$ satisfy $u_{0}<u<u_{2}$. Since $(d / d v) S\left[v ; u_{0}\right] \leqq$ $0, u_{0}<u<u_{2}$, it follows that

$$
S\left[v ; u_{0}\right] \geqq S\left[u ; v_{0}\right]
$$


for all $v \in\left(u_{0}, u\right)$. Hence $\left[u_{0}, u_{2}\right) \subset S\left(u_{0}\right)$. Similarly $\left(u_{1}, u_{0}\right] \subset S\left(u_{0}\right)$.

THEOREM 3.5. The point $u_{0}$ is an isolated point of $S\left(u_{0}\right)$ if, and only if, there is an interval $u_{1}<u_{0}<u_{2}$ such that $F^{\prime \prime}<0$ on $\left(u_{1}, u_{0}\right)$ and $F^{\prime \prime}>0$ on $\left(u_{0}, u_{2}\right)$.

NoтE. This theorem gives conditions under which it is not possible to shock from $u_{0}$ to any nearby value of $u$.

Proof. Suppose $u_{0}$ is an isolated point. If there did not exist $u_{2}>u_{0}$ such that $F^{\prime \prime}>0$ on $\left(u_{0}, u_{2}\right)$, then since the points of inflection are isolated, it follows that for some interval, $u_{0}<v<u_{2}, F^{\prime \prime}(u) \leqq 0$. But as seen before this implies $\left(u_{0}, u_{2}\right) \subset S\left(u_{0}\right)$, giving a contradiction. It follows similarly that there is $u_{1}<u_{0}$ such that $F^{\prime \prime}<0$ on $\left(u_{1}, u_{0}\right)$.

Conversely since $F^{\prime \prime}<0$ on $\left(u_{1}, u_{0}\right)$, by Lemma $2 S\left(u_{0}\right) \cap\left(u_{1}, u_{0}\right)=$ $\varnothing$. Similarly $S\left(u_{0}\right) \cap\left(u_{0}, u_{2}\right)=\varnothing$. Hence $u_{0}$ is isolated.

THEOREM 3.6. If $u_{1}$ is an interior point of $S\left(u_{0}\right)$ and if $F^{\prime \prime}\left(u_{1}\right) \neq$ 0 , then the jump from $u_{0}$ to $u_{1}$ is across a shock.

Proof. We must show that

$$
F^{\prime}\left(u_{0}\right)>S\left[u_{1} ; u_{0}\right]>F^{\prime \prime}\left(u_{1}\right) \text {. }
$$

For the sake of argument suppose that $u_{0}<u_{1}$. If $F^{\prime}\left(u_{0}\right)>S\left[u_{1} ; u_{0}\right]$ did not hold, then by Theorem $2.2 F^{\prime}\left(u_{0}\right)=S\left[u_{1} ; u_{0}\right]$. Since $u_{1}$ is an interior point, for some $\eta>0,\left(u_{1}-\eta, u_{1}+\eta\right) \subset S\left(u_{0}\right)$. If $v_{0} \in\left(u_{0}, u_{1}\right)$ and satisfies $S\left[v_{0} ; u_{0}\right]>S\left[u_{1} ; u_{0}\right]$, then $v_{0} \notin S\left(u_{0}\right)$. To see this note that $S\left[\tilde{u} ; u_{0}\right] \rightarrow F^{\prime \prime}\left(u_{0}\right)=S\left[u_{1} ; u_{0}\right]$ as $\widetilde{u} \rightarrow u_{0}$, and hence for $\tilde{u}>u_{0}$ sufficiently close to $u_{0}, S\left[v_{0} ; u_{0}\right]>S\left[\tilde{u} ; u_{0}\right]$. Thus Condition E cannot hold. Hence $S\left[v ; u_{0}\right]=S\left[u_{1} ; u_{0}\right] \forall v \in\left(u_{1}-\eta, u_{1}\right)$. Thus for $v \in\left(u_{1}-\eta, u_{1}\right) w=F(u)$ coincides with the line $L$ given by $w=S\left[u_{1} ; u_{0}\right]\left(u-u_{0}\right)+F\left(u_{0}\right)$, a contradiction of $F^{\prime \prime}\left(u_{1}\right) \neq 0$. Hence $F^{\prime \prime}\left(u_{0}\right)>S\left[u_{1} ; u_{0}\right]$ must hold.

Next assume $S\left[u_{1} ; u_{0}\right]=F^{\prime}\left(u_{1}\right)$. Since $S\left[v ; u_{0}\right] \geqq S\left[u_{1} ; u_{0}\right], u_{0}<v<$ $u_{1}$, the graph of $w=F(u)$ lies above the line $L$ for $v \in\left(u_{0}, u_{1}\right)$. Since $F^{\prime \prime}\left(u_{1}\right) \neq 0$ and since $L$ is tangent to $w=F(v)$ at $u_{1}$, the graph of $w=F(v)$ lies above $L$ for $v \in\left(u_{1}, u_{1}+\eta\right)=I$, where $\eta>0$. Hence, as is easily seen, $S\left[v, u_{0}\right]>S\left[u_{1} ; u_{0}\right], v \in I$, and therefore $I \cap S\left(u_{0}\right)=\varnothing$. Thus $u_{1}$ is a boundary point of $S\left(u_{0}\right)$, a contradiction. Hence (17) must hold.

\section{REFERENCES}

1. D. P. Ballou, Solution of non-linear hyperbolic Cauchy problems without convexity conditions, Trans. Amer. Math. Soc. 152 (1970), 441-460. 
2. Weak solutions with a dense set of discontinuities, J. Differential Equations, 10 (1971), 270-280.

3. P. D. Lax, Hyperbolic solutions of conservation laws II, Comm. Pure Appl. Math., 10 (1957), 537-566.

4. O. A. Oleinik, On discontinuous solutions of non-linear differential equations, Uspekhi Mat. Nauk., 12 (1957), 3-73. English translation, Amer. Math. Soc. Trans. Ser. 2, No. 26 , pp. 95-172.

5. J. A. Smoller, A survey of hyperbolic systems of conservation laws in two dependent variables, Hyperbolic Equations and Waves, Battelle Seattle 1968 Rencontres, SpringerVerlag, Berlin, (1970), 51-60.

6. A. I. Volpert, The spaces $B V$ and quasilinear equations, Math. USSR Sbornik, 2 (1967), 225-267.

7. Zhuo-Qun $\mathrm{Wu}, \mathrm{On}$ existence and uniqueness of generalized solutions of the Cauchy problem for quasilinear equations of first order without convexity conditions, Acta. Math. Sinica, 13 (1963), 515-530. English translation, Chinese Math., 4 (1964), 561-577.

Received March 2, 1971. This research was partially supported by National Science Foundation Grant GU 3171.

State University of New York at Albany 


\section{PACIFIC JOURNAL OF MATHEMATICS}

\section{EDITORS}

H. SAMELSON

Stanford University

Stanford, California 94305

C. R. HobBY

University of Washington

Seattle, Washington 98105
J. DUGUNDJI

Department of Mathematics

University of Southern California

Los Angeles, California 90007

RICHARD ARENS

University of California

Los Angeles, California 90024

\section{ASSOCIATE EDITORS}

E. F. BECKENBACH

B. H. NeumanN

F WoLF

K. YoshidA

\section{SUPPORTING INSTITUTIONS}

UNIVERSITY OF BRITISH COLUMBIA

UNIVERSITY OF SOUTHERN CALIFORNIA

CALIFORNIA INSTITUTE OF TECHNOLOGY

UNIVERSITY OF CALIFORNIA

MONTANA STATE UNIVERSITY

STANFORD UNIVERSITY

UNIVERSITY OF NEVADA

NEW MEXICO STATE UNIVERSITY

OREGON STATE UNIVERSITY

UNIVERSITY OF OREGON

OSAKA UNIVERSITY

UNIVERSITY OF TOKYO

UNIVERSITY OF UTAH

WASHINGTON STATE UNIVERSITY

UNIVERSITY OF WASHINGTON

$\stackrel{*}{*} \stackrel{*}{*} \stackrel{*}{*}{ }^{*}{ }^{*}$ MMEICAN MATHEMATICAL SOCIETY

NAVAL WEAPONS CENTER

Printed in Japan by International Academic Printing Co., Ltd., Tokyo, Japan 


\section{Pacific Journal of Mathematics}

\section{Vol. 42, No. $1 \quad$ January, 1972}

Tage Bai Andersen, On Banach space valued extensions from split faces ........

David Marion Arnold, A duality for quotient divisible abelian groups of finite

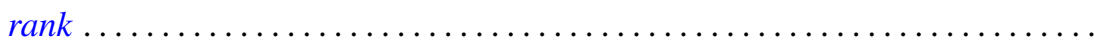

Donald Pollard Ballou, Shock sets for first order nonlinear hyperbolic

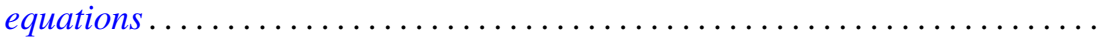

Leon Brown and Lowell J. Hansen, On the range sets of $H^{p}$ functions .........

Alexander Munro Davie and Arne Stray, Interpolation sets for analytic

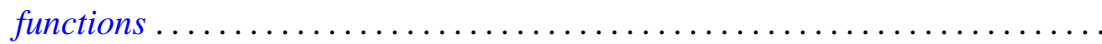

M. G. Deshpande, Structure of right subdirectly irreducible rings. II . . . . . . . . .

Barry J. Gardner, Some closure properties for torsion classes of abelian

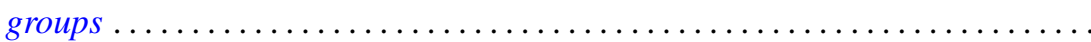

Paul Daniel Hill, Primary groups whose subgroups of smaller cardinality are

direct sums of cyclic groups . . . . . . . . . . . . . . . . . . .

Richard Allan Holzsager, When certain natural maps are equivalences .........

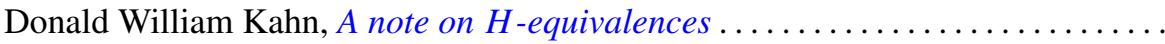

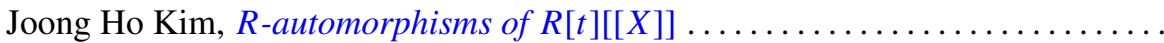

Shin'ichi Kinoshita, On elementary ideals of polyhedra in the 3-sphere.........

Andrew T. Kitchen, Watts cohomology and separability...

Vadim Komkov, A technique for the detection of oscillation of second order

ordinary differential equations .

Charles Philip Lanski and Susan Montgomery, Lie structure of prime rings of characteristic 2

Andrew Lenard, Some remarks on large Toeplitz determinants . .

Kathleen B. Levitz, A characterization of general Z.P.I.-rings. II .

Donald A. Lutz, On the reduction of rank of linear differential systems

David G. Mead, Determinantal ideals, identities, and the Wronskian ...

Arunava Mukherjea, A remark on Tonelli's theorem on integration in product

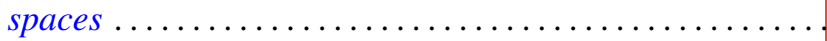

Hyo Chul Myung, A generalization of the prime radical in nonassociative rings.

John Piepenbrink, Rellich densities and an application to unconditionally nonoscillatory elliptic equations.

Michael J. Powers, Lefschetz fixed point theorems for a new class of multi-valued maps .

Aribindi Satyanarayan Rao, On the absolute matrix summability of a Fourier

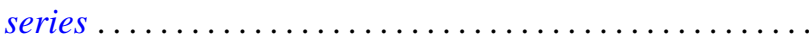

T. S. Ravisankar, On Malcev algebras ......................... 227

William Henry Ruckle, Topologies on sequences spaces . . . . . . . . . . . . . 235

Robert C. Shock, Polynomial rings over finite dimensional rings . . . . . . . . . 251

Richard Tangeman, Strong heredity in radical classes . . . . . . . . . . . . . . 259

B. R. Wenner, Finite-dimensional properties of infinite-dimensional spaces . . . . 267 